\title{
Staff Engagement Survey Pre- and 6-months Post Introduction of Routine Domestic Abuse Enquiry
}

\author{
R Sacks, N Ponnusamy, A Mears \\ Jefferiss Wing, St Mary's Hospital, London. Imperial College Healthcare NHS Trust
}

\section{Background}

Previous studies have demonstrated high prevalence of domestic abuse (DA) within Genitourinary medicine (GUM) attendees with rates as high as $47 \%$ in female GUM attendees ${ }^{1}$ (nearly twice the rates seen in women in the general population), with $50 \%$ of men-who-have-sex-with-men and $66 \%$ of transgender having a lifetime experience of $\mathrm{DA}^{2}$. The impact to the individual survivor, their families and society is unquantifiable but in financial terms it is estimated that DA costs the UK approximately 15.7 billion per year ${ }^{3}$. NICE has concluded that the cost of DA 'is so significant that even marginally effective interventions are cost effective' ${ }^{4}$. NICE explicitly recommends routine DA enquiry in all sexual health services.

Studies have shown that despite patients accepting, and in fact expecting, routine DA enquiry when they attend healthcare services ${ }^{5}$ there may be reluctance on the part of healthcare professionals to implement this. Reasons suggested for this resistance include not wanting to pry, feeling that DA is a Social Care issue, time pressures not knowing how to broach the subject or how to respond to and manage DA disclosures .

In July 2015, a routine DA enquiry was introduced for all patients attending the Jefferiss Wing walk-in GUM clinic, St Mary's Hospital, London. DA guidelines, proforma and management flowchart were devised. On-going, tiered training was, and continues to be, provided at a basic level for all staff, and in-depth for Sexual Health Information Practitioners (SHIP) and for those volunteering to act as DA champions.

As well as contemporaneous support from SHIP and DA champions, complex cases can be discussed in the weekly young persons (YP) Multidisciplinary Team (MDT) meeting or the monthly vulnerable adults MDT, which are both attended by members of the Trust safeguarding team. In addition, close links were forged with our local DA service Standing Together Against Domestic Violence, who provided the in-depth training and on-going advice and support for the core DA team. Lastly, to support the SHIP team members, who have the greatest involvement with patients disclosing DA, an in-house Clinical Psychologist provides regular one-toone supervision.

A survey was carried out to assess levels of staff engagement in routine DA enquiry both prior to and 6 months post roll-out.

\section{Method}

An on-line survey was disseminated to all GUM healthcare professionals within the service, two weeks prior to, and again 6 months post-introduction of, routine DA enquiry. Reminder emails were sent to staff during the two week period that both surveys were open, to encourage uptake.

\section{Results}

27 staff completed the pre-introduction and 20 completed the postintroduction surveys. The majority of respondents were female [70 vs. $90 \%$ ]. Respondents were doctors [48.1\% vs. $42.1 \%$ ], nurses [44.4\% vs. $57.9 \%]$ and healthcare assistants [7.4\% vs. $0 \%] .3 .7 \%$ vs. $20 \%$ had worked in GUM $<1$ year.

Although all staff had been offered training not all had attended $(87.5 \%$ vs $89.5 \%$ ). Of those that had had training, $33.3 \%$ vs $5.9 \%$ had received this in the month prior to each survey. $85.0 \%$ vs. $100 \%$ respectively had rated the training good-excellent.

${ }^{1} \mathrm{DV}$ in a GUM setting-an anonymous prevalence study in women Loke W et al IJSA 2008;19: 747-51 ${ }^{2}$ Stonewall Gay and Bisexual Men's Health Survey 2012 Guasp A

The Cost of Domestic Violence: Up-date 2009 Walby S (last accessed 25th June 2016)

http://www.lancaster.ac.uk/fass/doc library/sociology/Cost of domestic violence update.doc

${ }^{4}$ Domestic violence and abuse: multi-agency working. NICE Guidelines Feb 2014

${ }^{5}$ Women exposed to IPV: expectations + experiences when they encounter HCP: a meta-analysis of qualitative studies. Feder G et al. Archives of Internal Medicine 166: $22-37$ 2006

Copyright @ 2016 R Sacks, N Ponnusamy, A Mears Jefferiss Wing, St Mary’s Hospital, Imperial College Healthcare NHS Trust rachel.sacks@chelwest.nhs.uk
Table 1: Staff attitude to introduction of routine DA enquiry

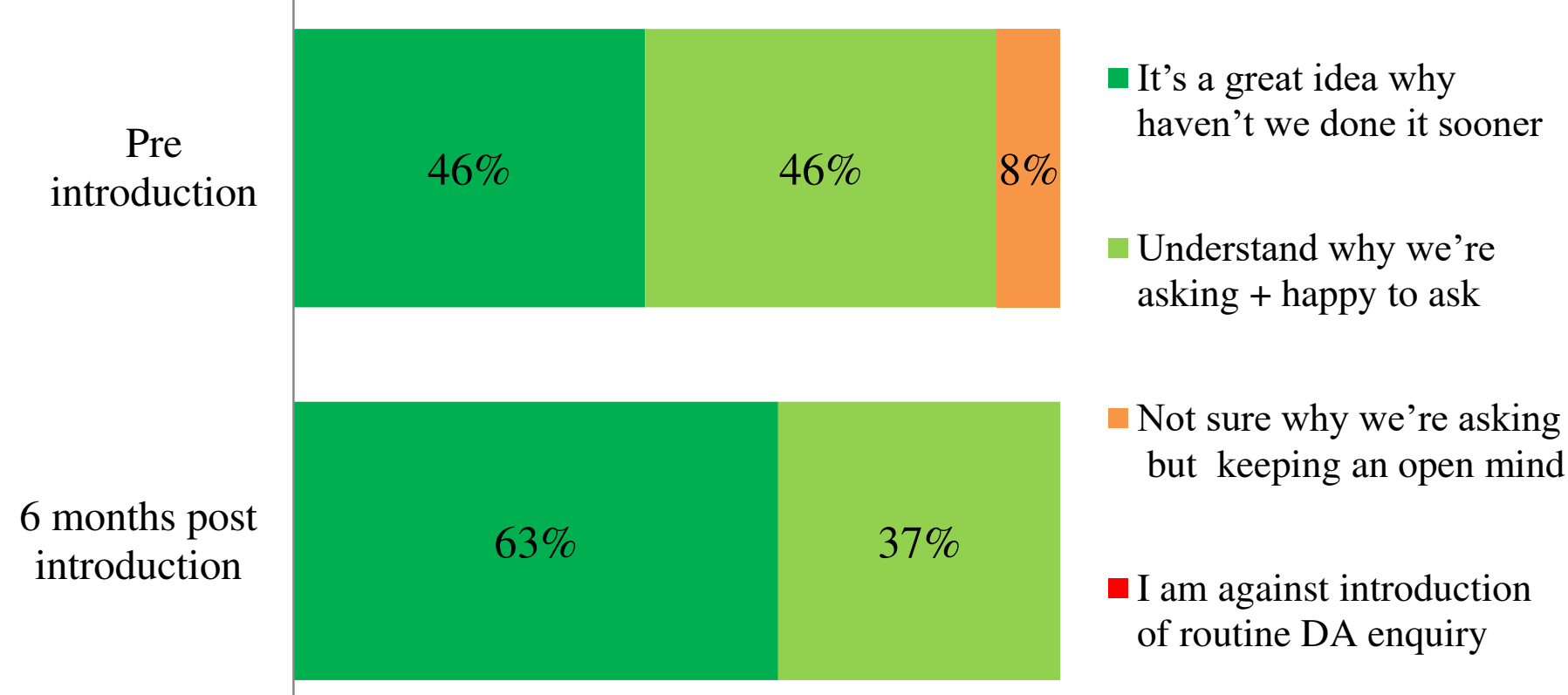

Table 2: Reported experience managing patients disclosing DA

\begin{tabular}{|l|c|c|} 
& Pre-introduction & $\begin{array}{c}6 \text { months post } \\
\text { introduction }\end{array}$ \\
\hline $\begin{array}{l}\text { Manage patients disclosing DA } \\
\text { at least once a week }\end{array}$ & $4.8 \%$ & $66.7 \%$ \\
\hline $\begin{array}{l}\text { Never managed patients } \\
\text { disclosing DA }\end{array}$ & $14.3 \%$ & $0 \%$ \\
\hline
\end{tabular}

Table 3: Reported confidence in asking patients about DA

\begin{tabular}{|l|c|c|}
\hline & Pre-introduction & $\begin{array}{c}6 \text { months post } \\
\text { introduction }\end{array}$ \\
\hline Very confident asking about DA & $16.7 \%$ & $63.2 \%$ \\
\hline
\end{tabular}

\section{Discussion}

Training was provided for all clinical staff working in the GUM clinic over the 3 months leading-up to the introduction of routine DA prompt. This resulted in high levels of staff engagement with the roll-out of routine DA enquiry even prior to introduction. This level of staff engagement increased further over the first 6 months, as seen in Table 1.

As experience in asking the routine DA prompt increased, staff confidence increased (Table $2+3$ ). There was also concerted and continued efforts to engage staff. These include on-going DA training and support for the team such as the addition of a part-time YP's worker, who helps with the management of YP experiencing DA, a monthly vulnerable adults MDT, where complex cases are discussed, and supervision for the SHIP team from our in-house clinical psychologist.

\section{Conclusion}

Positive staff engagement in routine DA enquiry was high from the outset and improved over 6 months. There was a remarkable increase in the proportion of staff that reported managing patients disclosing DA at least once a week (from 5\% pre-introduction to $67 \% 6$ months post) simply by introducing a routine DA prompt. Reassuringly confidence in asking the question markedly improved over this time, as levels of experience increased. We believe it is feasible to engage staff to routinely enquire about DA in a busy GUM service.

\section{Recommendations}

Training is planned for GUM reception staff and the aim is to roll out routine DA enquiry to the HIV service within the Jefferiss Wing. 